\title{
Lay-offs follow suspension of clinical trials of protein
}

London. Shares in the biotechnology startup company Regeneron Pharmaceuticals Inc, have fallen dramatically in value following the company's announcement that it has halted Phase III clinical trials of the protein ciliary neurotrophic factor (CNTF).

The company abandoned the trials, which it had been hoping would lead to a potential treatment for motor neurone disease, after it had come to the conclusion that a modification of the trial suggested by interim results reported in March would not be sufficient to eliminate the problems encountered.

As a result, the company will reduce its staff by 25 per cent to about 200. Most of those to leave have been directly involved with the phase III trials of CNTF. The company will write-off approximately $\$ 450,000$ over the next financial quarter to cover the redundancies.

The announcement that the clinical trials had been suspended was followed by a 17 per cent fall in the value of the companies' shares. Since then, the shares have remained around this level, with only small fluctuations in their value.

The decision to abandon the nine-monthold trial was made after it began to reveal side-effects in some of the 720 patients taking part. These included weight loss, coughs, the suppression of appetite and flulike symptoms.

CNTF is a cytosolic protein - one produced inside the cell - which has been shown to prevent the degeneration of neurones, both in animal models and in humans. Neurotrophic factors are seen as a potential treatment for amyotrophic lateral sclerosis (also known as motor neurone disease or MND), multiple sclerosis and other degenerative neurological diseases.

Regeneron had been testing CNTF for the treatment of MND, also known as Lou Gehrig's disease, a progressive degenerative disease of the motor neurones that causes gradual weakening and paralysis, initially in the arms and legs and eventually of the whole body. At present there is no treatment for MND, and the disease is fatal, usually within three to five years of diagnosis.

Michael Sendtner, of the department of neurochemistry at the Max-Planck-Institute for Psychiatry, who has worked extensively with CNTF in mice and rats, says he is not surprised by the trial results. "Our feeling is that they went too early to the clinic with the drugs," he says.

According to Sendtner, the potential side effects of the drug in clinical trials were discussed at a meeting in Birmingham in November 1992. The company "should have known" that there would be side effects, he says, suggesting that it might not have carried out enough work on the pharmacokinetics of the drug in humans, rather than merely studying animal models, before proceeding to phase III trials.

But Len Schleifer, chairman and chief executive officer of Regeneron, rejects this charge. "In the context of an untreatable deadly disease, I feel that we had sufficient basis to move forward to phase III," he says. In retrospect, he adds, the major problem with the trial was that the side-effects "played havoc" with attempts to measure the effectiveness of the drug.

Rather than pursuing CNTF further, Regeneron now plans to concentrate on the company's second generation CNTF and other neurotrophic factors. Schleifer says that the kind of setback which the company has experienced is common in the development of ground-breaking drugs.

"The shame is that because one trial didn't work, people assume that neurotrophic factors are dead," he says. But he maintains that neurotrophic factors are still the most promising avenue for the treatment of degenerative neurological diseases.

At the same time, however, the company is also fighting a class action lawsuit brought against it in March - when the initial results of the trials were announced indicating that it was running into problems - claiming that the company made "false and misleading" statements about the CNTF study.

According to the suit, this was done in order to "create and prolong the illusion of Regeneron's success in the biopharmaceutical industry, to inflate the price of the common stock of the company and to conceal the adverse facts concerning the company's future business prospects".

Schleifer claims that the shareholders are "totally baseless in what they say", and dismisses as "ludicrous" the suggestion that the company knew that the clinical trials would not work. "We were totally blind until shortly before the announcement," says Schleifer, adding that he plans to contest the action "vigorously".

Maggie Verrall

\section{UK research council splits peer review from policy inputs}

London. Britain's new Engineering and Physical Sciences Research Council (EPSRC) has unveiled details of a radical reorganization of its system for allocating research grants which will, for the first time, distinguish between its procedures for assessing grant applications and those for establishing research priorities.

Under the former Science and Engineering Research Council (SERC), which was abolished on March 31 this year, scientific committees had been responsible both for judging the scientific content of all applications received in their field of competence, and for making recommendations to the council about future funding for the field.

The EPSRC, created out of the break-up of the SERC following last year's white paper on science, gave its approval last week to a new set of procedures which, it hopes, will streamline both the grant review and the policy making processes, but will also create a "Chinese wall" between the two activities (see Nature 396, 3; 1994).

All grant applications will, once they have passed an initial screening by three referees, be assessed by an $a d$ hoc review panel whose members will be drawn from a 30-40 member 'college'.

Proposals will be ranked by this panel, in discussion with a programme manager from the EPSRC, who will also remind panels of the research councils strategic objectives. Once the ranking has been agreed, the funding of a particular application will depend on the amount of money which the council has made available for the field.

Inputs into discussions on future council policy, which were previously provided by the peer review committees, will now arrive by a separate route, namely through a "technical opportunities panel" responsible for identifying areas of scientific promise.

The so-called TOP panel will operate in parallel with a second 'users panel', and advice from the two panels will be used as the basis for the research council's funding applications from the government.

\section{OECD confirms drop in Japan's R\&D spending}

Paris. Figures released last week by the Organization for Economic Cooperation and Development in Paris have confirmed that, after ten years of rapid and continuous growth, funding for research and development (R\&D) in Japan fell sharply for the first time in 1992.

The decline in Japan followed that which had appeared at the end of the 1980 s in virtually all major Western economies. It was primarily the result of reduced $R \& D$ expenditures by Japanese industry, which fell by almost three per cent between 1991 and 1992 (see Nature 366,$97 ; 1993$ ).

Overall spending on R\&D by Japan dropped from 2.87 per cent of its gross domestic product (GDP) in 1991 to 2.80 in 1992. In contrast, US spending, which had fallen by 3.5 per cent from 1990 to 2.67 per cent of GDP in 1991, increased to reach 2.68 per cent of GDP in 1992. 